\title{
Digital Literacy Learning In Higher Education Through Digital Storytelling Approach
}

Banny S. K. Chan, The University of Hong Kong, China

Daniel Churchill, The University of Hong Kong, China

Thomas K. F. Chiu, The University of Hong Kong, China

\begin{abstract}
It is necessary to develop digital literacy skills with which students can communicate and express their ideas effectively using digital media. The educational sectors around the world are beginning to incorporate digital literacy into the curriculum. Digital storytelling, one of the possible classroom activities, is an approach which may help engage and motivate students to learn digital literacy skills. To investigate this approach, the present small-scale study employs the methods including interviewing and analysing the artefacts of three students selected from a purposive sample on a multimedia course. The findings indicate that the three students have improved in terms of three aspects of digital literacy skills, namely, digital competence, digital usage and digital transformation regardless of their prior knowledge and levels of digital literacy.
\end{abstract}

Keywords: Digital Literacy; Digital Storytelling; Engage; Motivate

\section{INTRODUCTION}

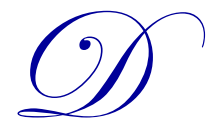

igital literacy skill is one of the essential skills for our current students. Students are required to express their ideas in digital media. Prior literature shows that students are required to equip the skills of viewing digital text and representing ideas in digital media to effectively communicate with others (Frazel, 2010; Jolls, 2008; Kress, 2003; Kress \& Van Leeuwen, 2006; Ohler, 2008). In higher education it is challenging to ensure that their students can effectively develop such digital literacy skills (Frazel, 2010).

A number of studies have revealed that adopting digital storytelling not only helps bridge the high-tech world outside the classroom and traditionally low-tech setting, but also motivates students to learn through the creation of personal stories (Ohler, 2008; Smeda, Dakich, \& Sharda, 2014; Ware, 2006). Digital storytelling provides an opportunity for students to solve problems and gain competence with technology through practice and experimentation (Kajder, 2004; Robin, 2008; Smeda, Dakich, \& Sharda, 2012). Robin (2008) points out that digital storytelling enables students to develop digital literacy through the use of technological tools in the video production process.

This study aims to investigate how to use digital storytelling activities to design a curriculum which can facilitate students' digital literacy in higher education. The study was conducted in a Hong Kong community college. The results have advanced the understanding of digital literacy development through digital storytelling activities (Barrett, 2006; Robin, 2006, 2008; Sadik, 2008). The findings reveal that the students' digital literacy has improved regardless of their prior knowledge in digital competence. This study also suggests that digital storytelling could offer pedagogical benefits of engaging and motivating students in the development of filming skills and learning of video editing skills through their reflection on deep learning, which could promote digital literacy development via digital storytelling activities. 


\section{Digital Literacy}

Digital literacy is defined as "the ability to understand and use information in multiple formats" with emphasis on critical thinking rather than information and communication technology skills (Gilster, 1997). Kress (2003) points out that the screen has become the major medium for communication. People require the skills to read and interpret the meaning of the digital text, symbols and graphs (Gee, 2003). According to Lankshear and Knobel (2003), people have new types of knowledge associated with "digitally saturated social practices". It is common for them to use the short messaging system via the "dominated modes of communication" such as Facebook, Twitter and YouTube (Ibrahim, Shariman, \& Woods, 2013). Digital literacy as well as media literacy and information literacy plays an import role in primary, secondary and higher education (Koltay, 2011). This is in line with the ideas advocated on the website of the "Framework for $21^{\text {st }}$ Century learning" (Partnership for 21st Century Learning, 2015). The framework reveals the definitions and meanings of skills and competences required in the $21^{\text {st }}$ century with emphasis on the educational needs (Voogt \& Roblin, 2012).

Digital literacy can be regarded as an umbrella framework of skills, knowledge and ethics (Calvani, Cartelli, Fini, \& Ranieri, 2008). Martin (2008) describes a digital literate person as someone with the ability to identify, access, manage, integrate, evaluate, analyse and synthesize digital resources. According to him, digital literacy can be conceived on three levels. Some authors emphasize cognitive and socio-emotional aspects while others focus on the technical skills (Eshet-Alkalai, 2004). Digital literacy changes from time to time.

Given the different definitions, digital literacy can be regarded as the ability to read, write, view, listen, compose and communicate information (Lankshear \& Knobel, 2008). Martin (2008) concluded that digital literacy could be conceived on three aspects including digital competence, digital usage and digital transformation.

Martin (2008) further explained that digital competence (Level I) is the crucial importance of "situational embedding" with the involvement of successful usage of digital media within life situation. The digital usage (Level II) is considered the application of digital competence within specific profession context, and digital usages become "embedded and evolved" with the community itself (Martin, 2008). The use of digital storytelling can effectively develop digital literacy (Robin, 2006). The digital transformation (Level III) is regarded as the achievement of contributing digital usage with innovation and creativity to the profession or knowledge domain (Martin, 2008). According to literature, digital literacy skills can develop through digital storytelling activities. Students could improve their digital competence by mastering basic skills for digital media creation with technological tools during the production stage of digital storytelling activities (Frazel, 2010; Ibrahim et al., 2013; Smeda et al., 2012). Sadik (2008) points out that digital storytelling enables students to use the new technology in an effective way, especially when they are engaged with digital resources and useful editing tools to create quality stories.

\section{Digital Storytelling}

Digital storytelling has been widely adopted in teaching and learning in educational sectors around the world (Blas \& Paolini, 2013; Hung, Hwang, \& Huang, 2012; Liu, Lu, Wu, \& Tsai, 2016; Mills, 2010; Ohler, 2006; Robin, 2008; Sadik, 2008). Digital storytelling is regarded as the art of telling stories with digital elements including text, graphics, sound and video (Robin, 2006). A typical digital story is a few minutes long narration with video and music to present ideas on a certain theme (Robin, 2008; Sadik, 2008). A digital story mainly has seven elements:

1. A point of view

2. A dramatic question

3. Emotional content

4. The gift of your voice

5. The power of the soundtrack

6. Economy

7. Pacing (Lambert, 2010, p. 7; Robin, 2008, p. 223)

Robin (2008) emphasizes that digital storytelling is a powerful tool which engages and motivates students in creating their own stories. Digital storytelling has four phases with seven steps (Chung, 2007; Gere, 2002; Kearney, 2011; 
Lambert, 2010; Ohler, 2006; Robin, 2006; Yang \& Wu, 2012). The details of the seven steps are summarized as follows:

1. Pre-production phase:

- Owning your insights

- Owning your emotions

- Finding the moment

2. Production phase:

- Seeing your story

- Hearing your story

3. Post-production phase:

- Assembling your story

4. Distribution

- Sharing your story (Lambert, 2010, pp. 7-22)

Students should be informed of the criteria for assessing the digital storytelling projects (Hofer \& Swan, 2006). According to Barrett (2006), the Scott County Digital Storytelling rubric is an appropriate tool for assessing digital stories. The assessment categories in the rubric mainly evaluate how well the seven elements in a digital story can be presented on the website of Rubistar (http://rubistar.4teachers.org/) with free resources for educators (Christopher, 2010; Merillat \& Ault, 2010). A rubric after modification with four scales, namely, emerging, basic, competence and exemplary was adopted by adding an item related to technological skills. Assessment components in the rubric mainly focus on the purpose and contents of the story, video shooting skills and video editing techniques. For example, the digital story may be scored competent if it can fulfil the following criteria in three aspects:

- The purpose of the story and the point of view are conveyed to the audience in a clear and effective manner.

- The choice of contents, clarity of voice, storyline and language use are clear and substantially included.

- The use of camera equipment, video shooting skills and video editing techniques are clear and often observable.

\section{Incorporating Digital Literacy into Digital Storytelling}

Students could effectively develop digital literacy through digital storytelling activities, for example, using technological tools including cameras, microphones and video editing software (Yuksel, Robin, \& McNeil, 2011). According to Barber (2016), the incorporation of multimedia elements into digital storytelling encourages video production and editing skills. Students can learn video editing skills to create video clips for digital storytelling activities (Clark, Couldry, MacDonald, \& Stephansen, 2015; Xu, Park, \& Baek, 2011). They can also use a variety of media and formats to present ideas and to share such ideas with others in a creative way. Digital storytelling is believed to be beneficial to students. The following sections will describe the pedagogical benefits brought by digital storytelling.

\section{Student Engagement}

Digital storytelling is regarded as a pedagogical tool which can engage students in their meaningful learning (Barber, 2016; Chigona, 2012; Gregory, Steelman, \& Caverly, 2009; Hill \& Grinnell, 2014; Tan, Lee, \& Hung, 2014). Students participate in the group project and create their digital stories. They are engaged in the "language of their generation" (Hofer \& Swan, 2006). The digital storytelling can provide an interesting learning environment for the "digital generation" students in the classroom (Barrett, 2006). Digital storytelling engages students in deep and meaning learning (Smeda et al., 2012). Student engagement can be regarded as a pedagogical benefit of digital storytelling (Hofer \& Swan, 2006; Smeda et al., 2012). 


\section{Reflection on Deep Learning}

Digital storytelling can provide other pedagogical benefits including motivation and reflection for deep learning (Barrett, 2006; Sadik, 2008; Smeda et al., 2014). It also promotes reflection on learning when students are provided with challenging tasks to integrate new learning into previous learning (Moon, 1999). Students work together in preparing the theme and storytelling of the story. Learning occurs in the story creation when students construct the storyline and tell the story based on the theme (McDrury \& Alterio, 2003). Deep learning occurs when students try to relate the ideas to their prior knowledge and experience and examine the logic and argument cautiously (Weigel, 2002). Therefore, the reflection of deep learning would be one of the pedagogical benefits of digital storytelling (Barrett, 2006; Moon, 1999; Weigel, 2002).

\section{Motivation}

Hung et al. (2012) found that students were engaged in digital story creation in a collaborative learning environment. Students worked together to prepare the plot, storyboard and script at the early stage of digital storytelling activities. They were motivated to create quality stories when they were engaged in an authentic learning environment (Sadik, 2008; Smeda et al., 2012). Motivation can be regarded as a pedagogical benefit of digital storytelling (Sadik, 2008; Smeda et al., 2012).

\section{Filming Skills Development}

At the production phase of digital storytelling activities, students shoot video based on the storyboard and script. Student could master the filming skills when they create their digital stories (Lambert, 2013). They learn how to use the camera, tripods and microphones in the video shooting process. Students learn to capture video at different shots and angles to express their ideas with the digital camera (Yuksel et al., 2011). Filming skills development can be regarded as one of the pedagogical benefits of digital storytelling (Lambert, 2013; Yuksel et al., 2011).

\section{Video Editing Skills Learning}

Video footage captured at the video shooting stage has to be edited (Clark et al., 2015). The incorporation of digital media such as video and graphics into digital storytelling could promote video editing skills (Barber, 2016). Digital story creation encourages students to learn video production and editing skills (Clark et al., 2015; Xu et al., 2011). Students could apply special effects and add music to promote the mood of the digital storyline. Therefore, video editing skills learning could be regarded as a pedagogical benefit of digital storytelling (Barber, 2016; Clark et al., 2015; Xu et al., 2011).

\section{Story Aspect}

In the digital storytelling process, students are free to choose the topics they like. Students are engaged in the brainstorming and story outline making about the story (Hung et al., 2012; Smeda et al., 2012). They are motivated to develop the storyline, storyboard and script of the story. Students are highly engaged in the digital story creation process (Hung et al., 2012). Story aspect could be regarded as pedagogical benefit brought by digital storytelling (Hung et al., 2012; Smeda et al., 2012).

To sum up, six pedagogical benefits brought by digital storytelling are listed. The next section explores how these pedagogical benefits improve digital literacy skills.

1. Student engagement (Hofer \& Swan, 2006; Smeda et al., 2012);

2. Reflection of deep learning (Barrett, 2006; Moon, 1999; Weigel, 2002);

3. Motivation (Hung et al., 2012; Sadik, 2008; Smeda et al., 2014);

4. Filming skills development (Lambert, 2013);

5. Video editing skills learning (Barber, 2016; Clark et al., 2015; Xu et al., 2011); and

6. Story aspects (Smeda et al., 2012) 


\section{THE PRESENT STUDY}

How to integrate digital storytelling in curricula in higher education can be explored more? The present study aimed to examine factors affecting the achievement of digital literacy when using digital storytelling. The factors include students' prior knowledge (levels of digital literacy) and the pedagogical benefits of the digital storytelling that influence digital literacy acquisition on a multimedia course (Barrett, 2006; Frazel, 2010; Robin, 2008; Sadik, 2008; Smeda et al., 2012, 2014).

\section{METHODS}

\section{Participants and Design}

Three participants with different levels of prior knowledge of digital competence from the three different project groups in the Multimedia Technology and Applications (MTA) course were selected as a purposive sample by referring to the personal reflective journal submitted at the beginning of the semester. Pseudonyms are used to safeguard against the anonymity of the participants who were studying in an associate programme at a Hong Kong community college with the mean age approximately 20. The participants' profiles are listed in Table 1.

In this study, we adopted the qualitative case study approach to study the phenomenon systematically and to seek holistic description and explanation (Merriam, 1988). Pre- and post- interviews were conducted to understand their process of acquiring digital literacy skills. The levels of digital literacy were identified by gauging the short video and the digital story submitted at the beginning and the end of the semester respectively. The backgrounds of the participants were described individually.

Table 1. Selection criteria of the three participants based on prior knowledge of digital competence.

\begin{tabular}{l|c|c|c|c}
\hline \multicolumn{1}{c|}{ Participant } & Year & Programme & Gender & $\begin{array}{c}\text { Prior knowledge of } \\
\text { digital competence }\end{array}$ \\
\hline Cindy & Two & Business Administration & Female & Middle \\
\hline Rita & Two & Financial Management & Female & Low \\
\hline Alex & One & Journalism & Male & High \\
\hline
\end{tabular}

\section{Cindy (Basic Skills)}

Cindy was a year-two student in the Business Administration programme. She had little experience in digital media creation. She edited a video clip on only one course before, but she was dissatisfied with the quality of the product. Her prior knowledge on digital competence was seen as middle. She was enthusiastic as she planned to get an excellent academic result in MTA.

\section{Rita (No Skills on Digital Media Creation)}

Rita was a year-two student in the Financial Management programme. She had no experience in creating digital media; she had no idea how to operate a camera for filming. Her prior knowledge in digital competence would be seen as low.

\section{Alex (With Some Skills on Video Shooting and Editing)}

Unlike other participants, Alex had created some videos before. He participated in the campus TV production in the secondary school, responsible for video shooting and editing in the athletic meet and other school ceremonies. He was year-one student in Journalism programme. His prior knowledge could be seen as high in digital competence.

\section{Materials}

The materials adopted in the present study comprised a short video and a digital story, pre- and post- interview questions, a personal reflective journal and a consent form from each participant. The first interview aimed to 
understand the prior knowledge based on the analysis of the short video. To measure digital literacy, the digital story was gauged based on a rubric with four scales emergent, basic, competent and exemplary adopted. The researchers could know how the students improve their digital literacy skills through the digital storytelling in the second interview.

\section{Procedure}

The researchers first briefed the director of the college on this study and obtained his consent. The participants were then informed with consent that they could join the study on voluntary basis and that they could quit at any time with their academic results not being affected.

In this study the learning period was 13 weeks. Students submitted a short self-introduction video in Week 4 . Then the students learned digital storytelling activities, and submitted a digital story in Week 13 . Two individual interviews for each participant were conducted after the submission of the first digital story at the end of the semester. The interviews were audio recorded.

The first author measured the levels of digital literacy with cross-check of another lecturer by assessing the short video and the corresponding digital story a rubric adopted from with modifications. Afterwards the interview transcripts were proof-read and analysed to explore how the participants' digital literacy developed. Based on the transcripts of the interviews, the initial codes of the activities and views were set. Interpretation of the meaning is required after analysing the qualitative data (Wolcott, 1994). The views and responses were counted. The coding and theme making help the researchers identify six factors that could promote digital literacy development. Some examples of quotations related to each of the factors are listed in Table 2.

Table 2. Examples of quotations related to benefits of digital storytelling.

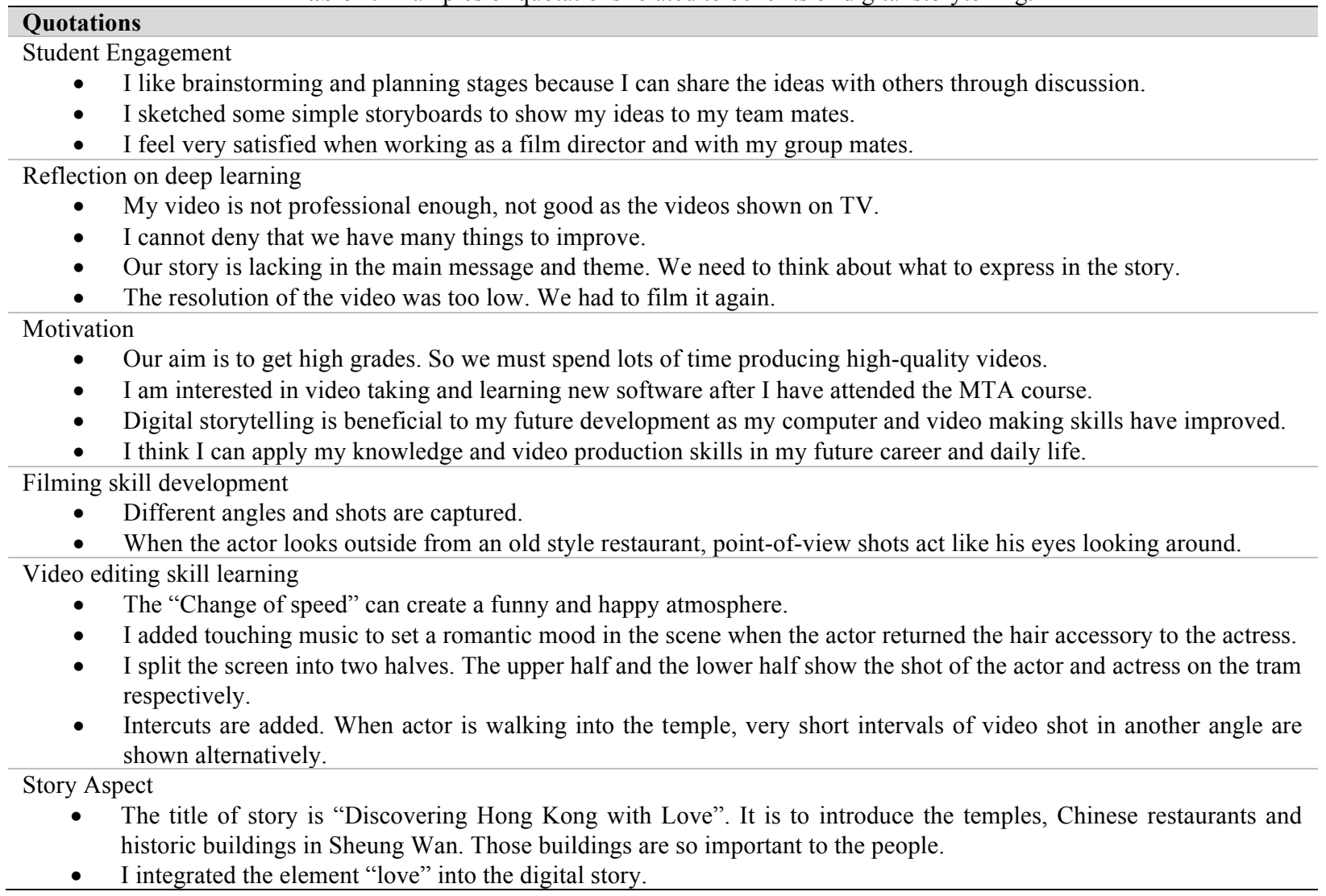




\section{RESULTS}

The data collected from the measurement of the short videos and the digital stories indicate that digital literacy development was reported favourably. The results show positive changes in all the three levels of digital literacy skills: the digital competence, digital usage, and digital transformation measured.

\section{The Development of Digital Literacy Skills by the Participants}

Regarding the development of digital literacy skills of each of the participants, Table 3 summarizes the levels of digital literacy before and after the completion of digital storytelling by the three participants. In general, the digital competence (Level I) improved from emerging to basic or competent, and from basic to exemplary; the digital usage (Level II) improved from emerging to basic or competent, and the digital transformation (Level III) improved from emerging to basic or competent.

Table 3. Participants' digital literacy skills before and after digital storytelling activities.

\begin{tabular}{c|c|c}
\hline \multicolumn{1}{|c|}{ Digital literacy } & Prior knowledge & After digital storytelling activities \\
\hline Cindy (pseudonym) & Emerging & Competent \\
Level I: Digital competence & Emerging & Competent \\
Level II: Digital usage & Emerging & Competent \\
Level III: Digital transformation & & \\
\hline Rita (pseudonym) & Emerging & Basic \\
Level I: Digital competence & Emerging & Basic \\
Level II: Digital usage & Emerging & Basic \\
Level III: Digital transformation & & \\
\hline Alex (pseudonym) & Basic & Exemplary \\
Level I: Digital competence & Emerging & Exemplary \\
Level II: Digital usage & Emerging & Competent \\
Level III: Digital transformation
\end{tabular}

Note: The measurement of digital literacy includes emerging, basic, competent and exemplary.

\section{Participant One: Cindy, Passionate in Digital Media Creation}

Cindy, who was studying in Business Administration programme in the community college, had little experience digital media creation before. The short video submitted at the beginning of the semester indicates that the digital literacy in terms of digital competence, digital usage and digital transformation was emerging (See Table 3). In the first interview, Cindy mentioned she was not satisfied with the quality of the artefact.

At the first stage (pre-production) of digital storytelling, Cindy reported that she was passionate for the MTA and hoped to achieve good academic performance. She was excited because she could decide on the theme of the digital story. After brainstorming with her group members, they decided to adopt a theme called "Discovering Hong Kong with Love" to introduce the streets, buildings, restaurants in Sheung Wan on Hong Kong Island with the element "love". After watching a couple of similar digital stories, she realized that quality videos required good skills in camera operation and special effects.

At the second stage (production) of digital storytelling, Cindy was eager to learn multimedia concepts and Adobe Premiere Pro for video editing. She was also passionate for the operation of digital camera, microphone and tripod. She hoped that the technical skills related to filming could be applied in the digital story because she believed that video editing skills could create an interesting and funny atmosphere. However, she found video quality such as sound quality and resolution captured for the first time was not good enough. She demonstrated her enthusiasm by revising the storyboard with detailed shots and angles. Some of sketches of the storyboard were shown in Figure 1. She believed that quality video required good planning and storyboard sketching to present ideas to the audience. After consulting the course lecturer on camera settings, she went to Sheung Wan again for video shooting. She mentioned that she did not mind although she had been to the same site for several times for filming because she liked video production. 
Cindy believed that the digital story would be boring and meaningless if she could not convey the feeling and atmosphere to the audience.

At the third stage (post-production) of storytelling, Cindy aimed to add more effects during video editing. "Lens flare" effects were applied to create sunshine, which made the atmosphere stronger. "Inter-cut" techniques (showing two different scenes alternately in a short interval of time) captured the moments when he touched the lamps from two different angles. She added romantic music "Meeting You" by an artist called Stefanie Sun to promote the mood when the actor met the actress finally by returning the hair accessory in an old building. Cindy also created a credit showing the crew members at the end of the digital story.

From the study of the digital story and Cindy's engagement in the digital storytelling activities, the researcher found she had acquired the following skills:

\section{$\underline{\text { Level I Digital Competence }}$}

Cindy's digital competence could be seen as competent (as in Table 3) after engaging in the digital storytelling activities, especially the earlier stage project planning. She tried hard to master technological skills such as operation of digital camera and video editing skills because she believed that the "more techniques can make video lifelike". She was motivated to create a quality artefact as she planned to obtain better academic results in all aspects. This could be regarded as a benefit brought by digital storytelling (Hung et al., 2012; Sadik, 2008; Smeda et al., 2014). Digital storytelling could engage her in filming skills development (Hofer \& Swan, 2006; Lambert, 2013; Smeda et al., 2012).

\section{$\underline{\text { Level II Digital usage }}$}

Cindy's digital usage could be considered competent (as in Table 3). She applied the skills including video shooting with different shots and angles and video editing skills with special effects at the video production stage based on the storyboard (See Figure 1). Some of the frames of the artefacts (See Figure 2) illustrate she was serious about digital story creation; for example she used different shots (wide shot at Frame 5, medium shot at Frame 10 and close-up shot at 17) and angles (low angle at Frame 11, high angle at Frame 7 and eye-level angle at Frame 14) to capture the street, temple and building. "Lens flare" effect was found in Frame 1 and the music was added in Frame 5. Her reflection on the learning process how to improve the camera shots and angles could be regarded as the pedagogical benefit of digital storytelling (Barrett, 2006; Moon, 1999; Weigel, 2002). Video editing skills learning could be encouraged with the adoption of digital story creation (Barber, 2016; Clark et al., 2015; Xu et al., 2011).

\section{Level III Digital transformation}

Cindy could achieve competent in digital transformation. She liked to discuss the storyline, storyboard and script writing preparation and how to effectively deliver the main message to the audience through introducing different places with the filming and video editing techniques with her members (See Figure 2). This could extend her creativity through story plots development to hold the interest of audience (Burgess, 2006; Daiute, 2015; Harmon \& Jhala, 2015; Ohler, 2008). Cindy created a digital story in a creative way by incorporating an element "love" into the theme of story of introducing different streets, temples, buildings and old-style restaurants. The freedom of the theme selection could be regarded as the story aspect, which could be one of the benefits brought by digital storytelling activities (Smeda et al., 2012). 
Figure 1. A simplified version of storyboard with the title: Discovering Hong Kong with Love.

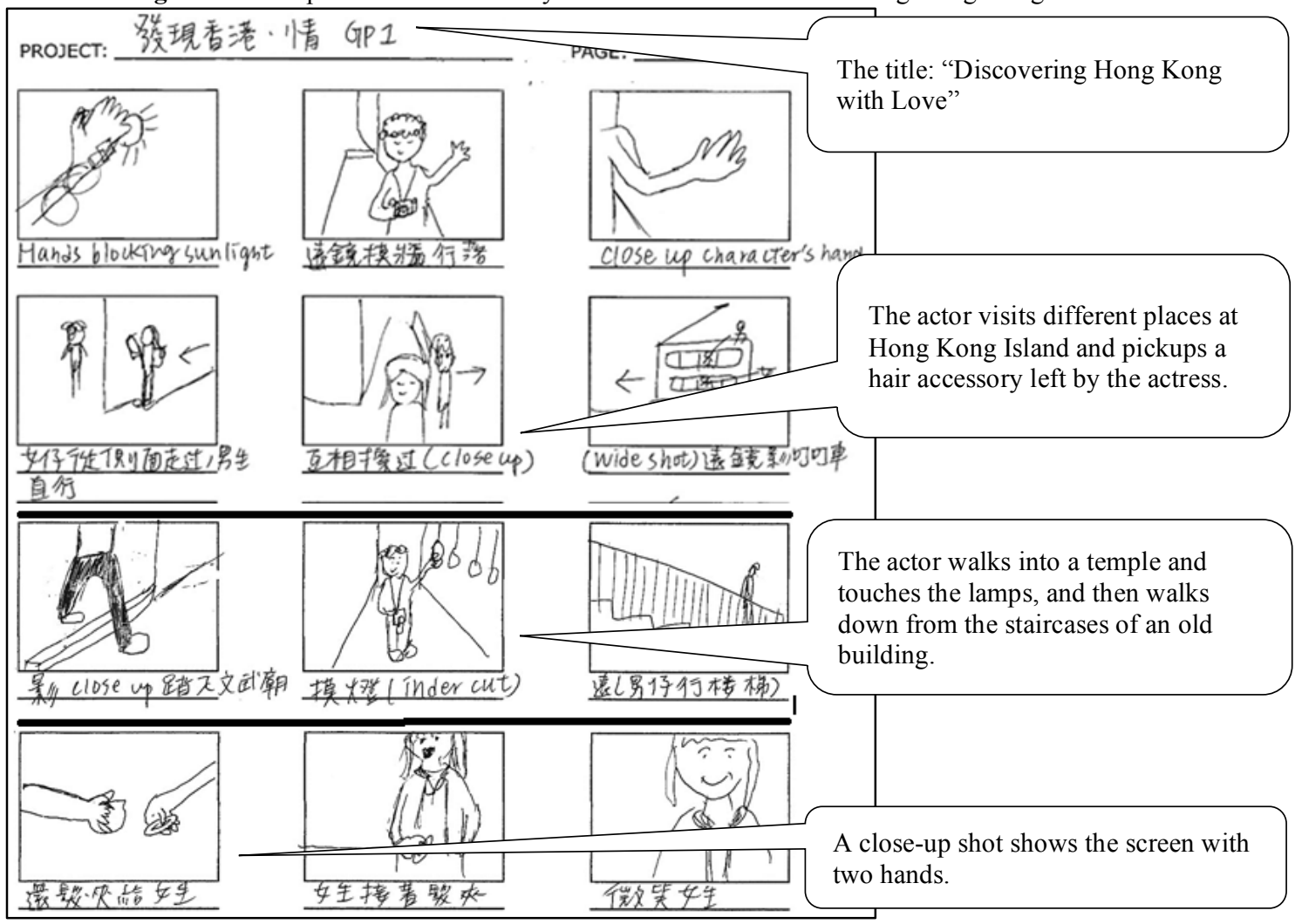

Figure 2. Frames extracted from Cindy's digital story.

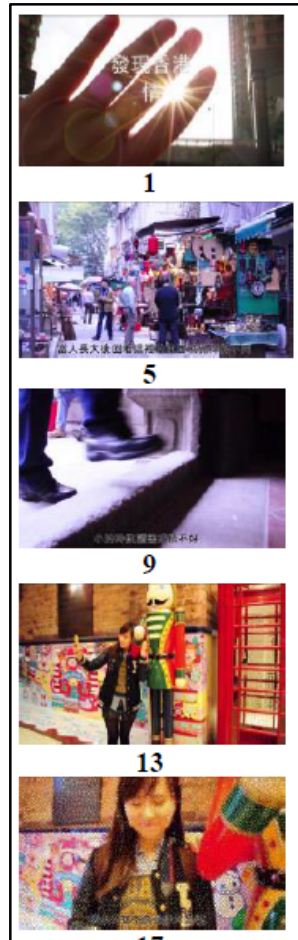

17

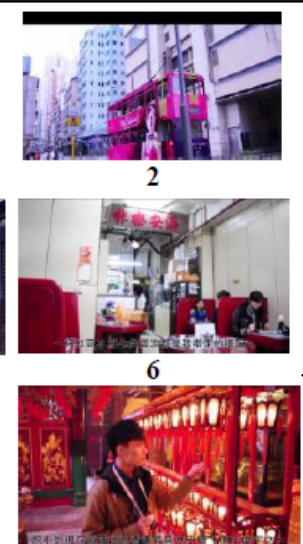

10

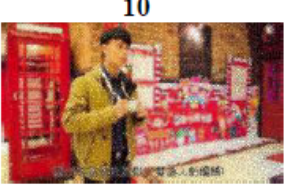

14

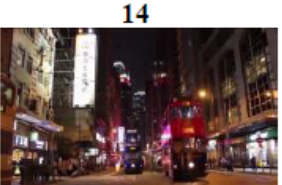

18
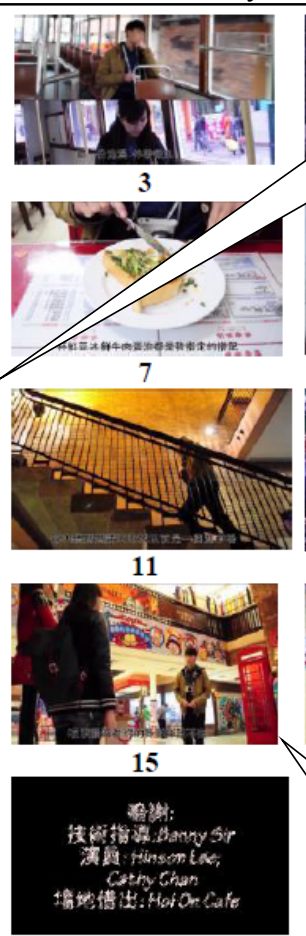

19
The actor walks into a

temple with low

angle...then he eats in a

Chinese restaurant.

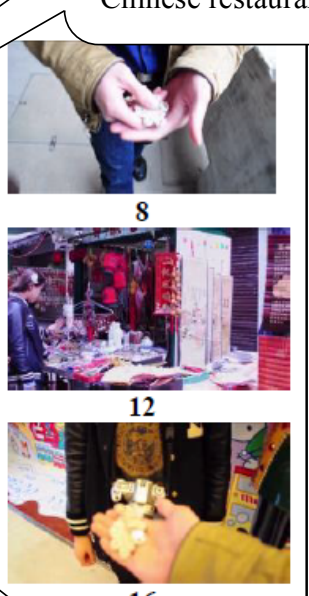

The actor returns the hair accessory to the actress, she feels happy. Romantic music is added. 
Participant Two: Rita (No Skills of Video Production)

Rita has gone through the same stages of digital storytelling activities. At the planning stage of digital storytelling, Rita discussed the theme of the storyboard and script with her members. The title of the digital story was "Cross Road". It is a narrative story about a young person who is pursuing a dream of being a badminton player. The actress cannot afford to spend time on her favourite sport for a couple of years since graduation. Until the moment she is tired of doing her current clerical job, she thinks about whether she should continue the job or pursue her dream to be an athlete. Finally, she makes a decision that she will play badminton at her leisure time while working.

At the production stage, she had difficulties with the basic operation of the camera such as focus control. She did not have any idea of what elements a digital story should include either. After being inspired by some sample video clips, she realized what "to do" and "not to do", and decided to create a digital story about the moment when the actress used to play badminton as a teenager. Rita started to master technical skills such as the use of digital camera and video editing. She realized that she had to learn photo and video editing skills. At the video production stage, she claimed that she had operated a digital camera for film. She found that it would be difficult to express her theme through the use of camera.

At the post-production stage of the project, she could apply some of the techniques including title and credits creation in Adobe Premiere Pro video editing software. She explained that she did not have enough time to fix the problem; part of the audio volume of voiceover was too low.

Regarding the plots, shots and angles, it was difficult for her to come up with the same idea as her group mates'. Finally, she compromised, and the digital story was created with appropriate techniques. She mentioned that video editing technique could benefit her career in the future; she learned how to communicate with others in the project.

\section{$\underline{\text { Level I Digital Competence }}$}

Rita's digital competence could be considered basic as she could master some of the techniques of camera operation and video editing, concepts of digital media and choice of contents for digital story creation. She was also engaged in all the activities of digital storytelling.

\section{Level II Digital Usage}

Rita's digital usage could be considered basic as she could develop her digital with the application of the skills she learned, including video shooting and video editing, although a small portion of live sound and voiceover was not clear enough.

\section{Level III Digital Transformation}

Rita's digital transformation could be considered basic. Her digital story shows that the purpose and point-of-view could be conveyed to the audience in a fairly effective manner. She mentioned that video editing technique could benefit her career in the future; she learned how to communicate with others in the project.

\section{Participant Three: Alex (with Video Production Skills)}

Alex had experience in digital video creation. He realized that the key elements of a good digital story should include not only storyline and script writing, but also technical skills. He even put more effort into video production techniques, including filming and video editing. He mentioned that he also learned special effects, such as slow and fast motion, colour change and other advance techniques in Adobe Premiere Pro, and that learning from mistakes helped him prepare better in the next project. First, he realised the first digital artefact was unsatisfactory owing to some difficulties encountered, for example, poor light source and inappropriate camera angles. This was because he failed to adjust the camera angle to avoid "back light". Second, it was so difficult to locate or trace the right video footages captured by two different cameras. Third, it was also a problem to "synchronize" video and audio tracks of two video clips taken by two different cameras in the timeline of Adobe Premiere Pro software. He reflected that he 
would try hard to learn the video shooting and editing skills in class. During a group discussion led by the course lecturer, he was inspired by certain sample videos. He explained that he had learned the merits exemplary digital stories should have and gained insights into how to produce a quality digital story.

In the first phase of digital storytelling, Alex was engaged enthusiastically in the group discussion on the theme "Give Me Five" about a teenager girl pursuing her dream to be journalist no matter what difficulties she might face. Finally, the actress' dream comes true; with the help and encouragement from her friends she manages overcome the obstacles during her studies. He played an active role in the preparation of the storyline, storyboard and script writing of the digital story. He even discussed and shared his own experience with his group members who did not have prior knowledge of digital media creation.

In the second phase of digital storytelling, Alex explained that learning Adobe Premiere Pro was very useful because he could master the skills like the use of filters, trimming video, creation of subtitles and credits, and video and audio transitions. He realized that the filming would be a challenging task with the constraints, for example limited time for filming, operation of video shooting tools, uncertainty of weather during filming, division of labour, voiceover recording and technical skill on video editing. In the end, all the tasks in video production could be completed smoothly.

In the third phase, a digital story was edited with effects, inter-cuts, such as subtitles and credits based on the storyboard and script. In one of the scenes, when the actress falls down accidentally in the corridor of the classroom, the scene turns to black and white from colour; sad music with slow tempo was added. In the final part of the story, fast tempo music was added when the actress' dream comes true.

\section{Level 1 Digital Competence}

Alex achieved exemplary in digital competence as he demonstrated he was engaged in mastering the skills of filming including the operation of two cameras in video shooting based on the storyboard. He was motivated to learn special effects in class for video editing and share his experience with group members.

\section{Level II Digital Usage}

Alex could be regarded as exemplary in digital usage as he could apply the skills learned at the production stage. He demonstrated good planning and commitment to overcoming the problems such as time constraints, camera equipment, and skill issues of his group members.

\section{Level III Digital Transformation}

Alex could be regarded as competent in digital transformation. He was motivated to prepare the plots of the story, storyboard sketching and contents selection to express his ideas to the audience. The freedom to select themes and to present the story from his own point of view would promote creativity development (Burgess, 2006; Daiute, 2015; Harmon \& Jhala, 2015; Ohler, 2008).

\section{Summary of Digital Literacy Development of the Three Participants}

In this study, the levels of digital literacy among the three participants improved. The participants could achieve higher digital literacy for the same prior knowledge for the cases of Cindy and Rita (See Table 3). The reasons why Cindy had greater improvement in digital literacy than Rita could be: (a) Cindy's enthusiasm in the engagement of storyboard preparation, script writing, filming skills learning and video editing skills development, (b) her motivation to produce quality videos for better academic results, and (c) her willingness to contribute to the development of the storyline based on the theme.

However, the participants with more advanced prior knowledge of digital competence could achieve higher levels of digital literacy in the cases of Alex and Cindy. For example, Cindy achieved competent from emerging, and Alex achieved exemplary from basic after digital storytelling activities. Alex was even the best in terms of digital literacy 
development among the three participants. He had better prior knowledge of digital competence. He was engaged in all the digital storytelling activities from the early stage of storyline and storyboard preparation to the later stage of video editing tasks.

The course lecturer could be a factor affecting the development of digital literacy. The lecturer might need to give advice to the students in need during the digital storytelling activities. This could help them learn better.

\section{The Effects of Digital Storytelling Pedagogy on Digital Literacy Development}

After the transcripts of the interviews had been analysed, the view and responses of perspective themes were counted. Table 4 summarises the factors promoting the digital literacy development of the three participants through digital storytelling activities.

Table 4. Factors affecting the development of digital literacy skills.

\begin{tabular}{c|c|c|c|c|c|c|}
\hline $\begin{array}{c}\text { Total views } \\
\text { and responses } \\
(\boldsymbol{n})\end{array}$ & $\begin{array}{c}\text { Student } \\
\text { engagement }\end{array}$ & $\begin{array}{c}\text { Reflection on } \\
\text { deep learning }\end{array}$ & Motivation & $\begin{array}{c}\text { Filming skill } \\
\text { developing }\end{array}$ & $\begin{array}{c}\text { Video editing } \\
\text { skill learning }\end{array}$ & Story Aspect \\
\hline Cindy & 11 & 29 & 13 & 17 & 17 & 13 \\
100 & $11.0 \%$ & $29.0 \%$ & $13.0 \%$ & $17.0 \%$ & $17.0 \%$ & $13.0 \%$ \\
\hline Rita & 5 & 32 & 11 & 14 & 14 & 8 \\
84 & $6.0 \%$ & $38.1 \%$ & $13.1 \%$ & $16.7 \%$ & $16.7 \%$ & $9.5 \%$ \\
\hline Alex & 9 & 21 & 5 & 11 & 9 & 7 \\
62 & $14.5 \%$ & $33.9 \%$ & $8.1 \%$ & $17.7 \%$ & $14.5 \%$ & $11.3 \%$ \\
\hline
\end{tabular}

The findings indicate the basic skill improved with the influential factor reflection on deep learning followed by filming and video editing skills. Cindy explained that she had been to the same location for filming again as she reflected parts of video clip were not good enough. For example, she mentioned the resolution of the video clip was too low and she would do it again. Alex also reflected that he would improve the video quality during video editing. He tried to learn more advanced skills such as filters, audio and video transitions, and "old film" style effects to further enhance the digital story. Alex explained that he had made use of voiceover and subtitles together to overcome audio volume problem in one of the video clips, instead of filming again owing to limited time.

Digital usage could be improved by the influential factor of story aspect with motivation and engagement in digital story creation. Cindy was motivated to produce a high-quality digital story with the skills she had learned after viewing some sample digital stories. Cindy claimed that it would be meaningful to integrate the element "love" to the story to introduce streets, buildings, temples and restaurants. She was engaged in the group work to develop the storyline, storyboard and script as she could freely select the theme of digital story and express her point of view to the audience. This could provide a way to extend her creativity to apply the skills in her profession (Burgess, 2006; Daiute, 2015; Harmon \& Jhala, 2015).

\section{DISCUSSION}

This study addressed the issue of how Hong Kong community college students develop digital literacy through digital storytelling activities. Digital literacy can be conceived on three levels: digital competence, digital usage, and digital transformation (Martin, 2008).

Students improved the digital competence (Level I) regardless of their prior knowledge of digital competence through digital storytelling. Students mastered techniques such as multimedia concepts, voiceover recording, operation of digital camera for filming, and video editing software package at the pre-production stage of digital storytelling. This could be regarded as the pedagogical benefit of digital storytelling to engage students in developing filming skills (Lambert, 2013). 
Digital usage (Level II) was enhanced through the application of the skills such as filming skill and video editing for digital story creation at the production stage and post-production phase. Students were more motivated in the creation of digital stories, compared with transitional classroom settings (Hung et al., 2012; Sadik, 2008; Smeda et al., 2014). They would make use of the skills such as the use of camera shots and angles with special effects to capture the scenes based on the storyboard to communicate with the audience in the production phase. Students might capture some of the shots or edit part of the video again for better quality in the post-production phase. The reflection of deep leaning would be seen a pedagogical benefit by digital storytelling (Barrett, 2006; Moon, 1999; Weigel, 2002). Students were motivated to learn more filming techniques and video editing skills themselves.

Students could enhance digital transformation in the pre-production phase. Students learned how to develop the storyline, storyboard sketching and select contents to express their ideas. They are free to choose their own themes of digital stories in an authentic learning environment. This would promote their creativity development (Burgess, 2006; Daiute, 2015; Harmon \& Jhala, 2015; Ohler, 2008).

\section{The Effects of Digital Storytelling}

Digital storytelling could be considered a pedagogy which could engage students and provide them with an authentic learning environment to develop digital literacy (Alexander, 2011; Miller, 2014; Robin, 2008; Sadik, 2008). It was observed that the digital storytelling activities, including storyboard drawing, script writing, use of camera, video shooting, narration recording, video editing and sharing, can help the learners master the basic skills, concepts, and use of digital media. This suggests that through digital storytelling, students may develop their creativity and innovation in expressing their ideas with digital media (Burgess, 2006; Daiute, 2015; Harmon \& Jhala, 2015; Ohler, 2008). Students could even apply the knowledge and skills on other courses and/or in future work. The findings of this study indicate levels of digital literacy could develop through digital storytelling activities, which is consistent with those in other studies (Frazel, 2010). The convergence of digital storytelling in education provides a good technological tool for collecting, creating, analysing and combining digital images with text in the video (Robin, 2008). The "multimedia-rich" digital story plays an important role in engaging students in learning technological skills (Robin, 2008). Regarding the development of digital literacy, Table 5 summarises the possible skills and concepts that might be learnt after the completion of digital storytelling.

Table 5. The skills and concepts mastered in the digital storytelling.

\begin{tabular}{|c|c|}
\hline Digital literacy & Skills mastered in digital storytelling activities \\
\hline $\begin{array}{l}\text { Level I: } \\
\text { Digital Competence }\end{array}$ & $\begin{array}{l}\text { - } \quad \text { Collecting and analyzing digital media } \\
\text { - } \quad \text { Photo and video editing skills } \\
\text { - } \quad \text { Using camera, microphone and tripod } \\
\text { - } \quad \text { Voice over recording in a quiet place for better quality }\end{array}$ \\
\hline $\begin{array}{c}\text { Level II: } \\
\text { Digital Usage }\end{array}$ & 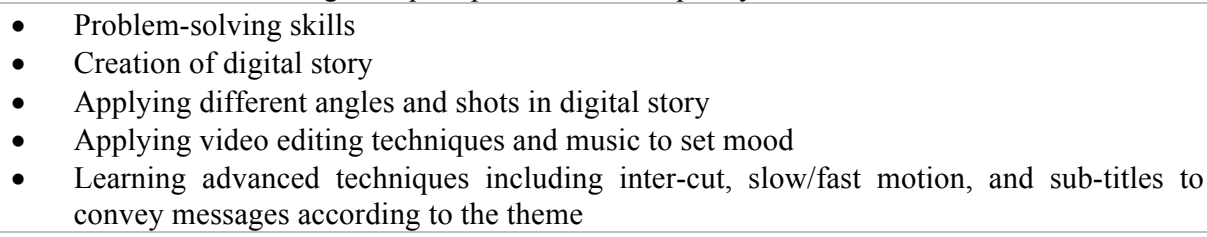 \\
\hline $\begin{array}{l}\text { Level III: } \\
\text { Digital Transformation }\end{array}$ & 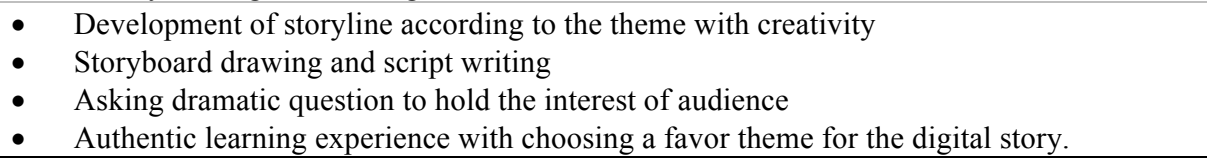 \\
\hline
\end{tabular}

The authors suggest organizing digital storytelling competitions of particular courses could engage and motivate students in learning subject matters deeper while developing digital literacy skills.

\section{Implications}

This study offers four implications for developing students' digital literacy skills in community colleges. First, the design of digital storytelling should cater for different students for example, students with basic skill should focus on 
reflection on deep learning. The findings of this study indicate students could learn more filming and video editing skills when they improved the quality of digital stories. Second, the design of curriculum should provide freedom for students to select the themes of their stories. Students would be engaged and motivated to develop their artefacts. Third, professional training workshops on digital storytelling should be offered to teachers to get them familiar with digital storytelling activities. Teachers may need to give guidance and feedback to students. Fourth, the college management should consider spending extra resources for conducting digital storytelling activities in the classroom. More computer systems with video editing software packages and technical support might be required.

\section{LIMITATIONS AND RECOMMENDATIONS}

Like many other studies of the same nature, the present study also has limitations. Only the students from one course were studied; more students should have been involved. Future studies should focus on the digital literacy development on different courses with the digital storytelling incorporated in the curriculum. Moreover, longitudinal studies should be helpful in ascertaining how digital literacy can help improve students' academic performances.

\section{CONCLUSION}

The main aim of this study is to investigate how college students develop digital literacy through digital storytelling activities. The results of the present study suggest that the students' digital literacy in terms of digital competence, digital usage, and digital transformation developed. Such results seem to be in line with the pedagogical benefits of digital storytelling with student engagement, reflection on deep learning, motivation, filming skill developing, video editing skill learning and story aspect (Matthews, 2014; Sadik, 2008; Smeda et al., 2012; Stewart \& Gachago, 2016).

An authentic learning environment provided in the early stage of digital storytelling engages and motivates students in learning process in the plot of a story, storyboards and script preparation. Students have the degree of freedom to choose the contents to match the theme. This may allow students to extend their creativity in developing the storyline for the narrative story. Students always try to produce quality digital stories from different angles, and with different shots, special effects and music, and to communicate with the audience with technological tools for video shooting and editing such as cameras, microphones, tripods, and video editing packages. Students in the group could reflect what they have done and what to improve in one stage before moving onto the next one. This also helps students apply the skills in their digital stories. It can be concluded that given the findings, digital storytelling seems to be an appropriate approach to developing digital literacy skills for community college students.

The findings are believed to be able to provide the education sector with useful guidelines when digital storytelling activities are incorporated into the curriculum.

\section{DISCLOSURE STATEMENT}

No potential conflict of interest was reported by the authors.

\section{AUTHOR BIOGRAPHIES}

Banny S. K. Chan is an EdD research candidate at the Faculty of Education, The University of Hong Kong, Hong Kong. His current research topic is to explore the digital literacy development of community college students through digital storytelling. E-mail: banny@hku.hk (corresponding author)

Daniel Churchill is an associate professor at the Faculty of Education at The University of Hong Kong. His research interests include educational technology, instructional design, mobile learning and multimedia. E-mail: dchurch@hku.hk

Thomas K. F. Chiu is a lecturer at the Faculty of Education at the University of Hong Kong. He specialises in technology adoption, multimedia design, instructional design and IT in education. E-mail: tchiu@hku.hk 


\section{REFERENCES}

Alexander, B. (2011). The new digital storytelling: creating narratives with new media. Santa Barbara, Calif: Praeger.

Barber, J. F. (2016). Digital storytelling: New opportunities for humanities scholarship and pedagogy. Cogent Arts \& Humanities, 3(1), 1181037. doi: 10.1080/23311983.2016.1181037

Barrett, H. (2006). Researching and evaluating digital storytelling as a deep learning tool. Technology and Teacher Education Annual, $1,647$.

Blas, N. D., \& Paolini, P. (2013). Beyond the School's Boundaries: PoliCultura, a Large-Scale Digital Storytelling Initiative. Journal of Educational Technology \& Society, 16(1), 15.

Burgess, J. (2006). Hearing Ordinary Voices: Cultural Studies, Vernacular Creativity and Digital Storytelling. Continuum: Journal of Media \& Cultural Studies, 20(2), 201-214. doi: 10.1080/10304310600641737

Calvani, A., Cartelli, A., Fini, A., \& Ranieri, M. (2008). Models and instruments for assessing digital competence at school. Journal of e-Learning and Knowledge Society, 4(3), 183-193.

Chigona, A. (2012). Pre-service students' perceptions and experiences of digital storytelling in diverse classrooms. Turkish Online Journal of Educational Technology, 11(3), 278-285.

Christopher, L. (2010). Digital Storytelling. Handbook of Research on Transformative Online Education and Liberation: Models for Social Equality: Models for Social Equality, 408.

Chung, S. K. (2007). Art education technology: Digital storytelling. Art Education, 60(2), 17-22.

Clark, W., Couldry, N., MacDonald, R., \& Stephansen, H. C. (2015). Digital platforms and narrative exchange: Hidden constraints, emerging agency. New Media \& Society, 17(6), 919-938.

Daiute, C. (2015). Tensions of Plot in Interactive Digital Storytelling. In H. Schoenau-Fog, E. L. Bruni, S. Louchart \& S. Baceviciute (Eds.), Interactive Storytelling: 8th International Conference on Interactive Digital Storytelling, ICIDS 2015, Copenhagen, Denmark, November 30 - December 4, 2015, Proceedings (pp. 40-49). Cham: Springer International Publishing.

Eshet-Alkalai, Y. (2004). Digital Literacy: A Conceptual Framework for Survival Skills in the Digital Era. Journal of Educational Multimedia and Hypermedia, 13(1), 93.

Frazel, M. (2010). Digital storytelling guide for educators (1st ed.). Eugene, Or: International Society for Technology in Education.

Gee, J. P. (2003). What video games have to teach as about learning and literacy? (1st ed.). New York: Palgrave Macmillan.

Gere, J. (2002). Storytelling tools for the classroom. In J. Gere, B. A. Kozlovich \& D. A. I. Kelin (Eds.), By word of mouth: A storytelling guide for the classroom (pp. 1-8). Hawaii: Pacific Resources for Education and Learning.

Gilster, P. (1997). Digital literacy. New York: John Wiley \& Sons.

Gregory, K., Steelman, J., \& Caverly, D. C. (2009). Techtalk: Digital Storytelling and Developmental Education. Journal of Developmental Education, 33(2), 42-43.

Harmon, S., \& Jhala, A. (2015). Revisiting Computational Models of Creative Storytelling Based on Imaginative Recall. In H. Schoenau-Fog, E. L. Bruni, S. Louchart \& S. Baceviciute (Eds.), Interactive Storytelling: 8th International Conference on Interactive Digital Storytelling, ICIDS 2015, Copenhagen, Denmark, November 30 - December 4, 2015, Proceedings (pp. 170-178). Cham: Springer International Publishing.

Hill, S., \& Grinnell, C. (2014). Using digital storytelling with infographics in STEM professional writing pedagogy 2014 IEEE International Professional Communication Conference (IPCC) (pp. 1-7). Pittsburgh: IEEE.

Hofer, M., \& Swan, K. O. (2006). Digital storytelling: Moving from promise to practice. In C. Crawford (Ed.), Proceedings of Society for Information Technology and Teacher Education International Conference 2006 (pp. 697-684). Chesapeake, VA: AACE.

Hung, C. M., Hwang, G. J., \& Huang, I. (2012). A Project-based Digital Storytelling Approach for Improving Students' Learning Motivation, Problem-Solving Competence and Learning Achievement. Journal of Educational Technology \& Society, 15(4), 368.

Ibrahim, N., Shariman, T. N. T., \& Woods, P. (2013). The Concept of Digital Literacy from the Perspective of the Creative Multimedia Industry 2013 International Conference (pp. 259-264): IEEE.

Jolls, T. (2008). Literacy for the 21st Century: An Overview \& Orientation Guide to Media Literacy Education: Center for Media Literacy.

Kajder, S. (2004). Enter her: Personal narrative and digital storytelling. English Journal, 93(3), 64-68.

Kearney, M. (2011). A learning design for student-generated digital storytelling. Learning, Media and Technology, 36(2), 169188. doi: 10.1080/17439884.2011.553623

Koltay, T. (2011). The media and the literacies: media literacy, information literacy, digital literacy. Media, Culture \& Society, $33(2), 211-221$.

Kress, G. R. (2003). Literacy in the new media age. London: Routledge.

Kress, G. R., \& Van Leeuwen, T. (2006). Reading Images: The Grammar of Visual Design (2nd ed.). Florence: Routledge.

Lambert, J. (2010). Digital storytelling cookbook: Digital Dinner Press.

Lambert, J. (2013). Digital storytelling: capturing lives, creating community. New York: Routledge. 
Lankshear, C., \& Knobel, M. (2003). New literacies: changing knowledge and classroom learning. Buckingham England: Open University Press.

Lankshear, C., \& Knobel, M. (2008). Digital literacies: concepts, policies and practices: New York: Peter Lang.

Liu, C. C., Lu, K. H., Wu, L. Y., \& Tsai, C. C. (2016). The Impact of Peer Review on Creative Self-efficacy and Learning Performance in Web 2.0 Learning Activities. Journal of Educational Technology \& Society, 19(2), 286.

Martin, A. (2008). Digital Literacy and the "Digital Society". In C. Lankshear \& M. Knobel (Eds.), Digital Literacies: Concepts, Policies and Practices (pp. 151-176). New York: Peter Lang.

Matthews, J. (2014). Voices from the heart: The use of digital storytelling in education. Community Practitioner, 87(1), 28-30.

McDrury, J., \& Alterio, M. (2003). Learning through storytelling in higher education : using reflection \& experience to improve learning. London; Sterling, VA: Kogan Page.

Merillat, L., \& Ault, M. (2010). Teaching and Learning about Rubrics Using RubiStar. Paper presented at the Society for Information Technology \& Teacher Education International Conference.

Merriam, S. (1988). Case study research in education: A qualitative approach. San Francisco: Jossey-Bass.

Miller, C. H. (2014). Digital storytelling: a creator's guide to interactive entertainment (Vol. 3rd). Burlington, Mass: Focal Press.

Mills, K. A. (2010). A Review of the "Digital Turn" in the New Literacy Studies. Review of Educational Research, 80(2), 246271. doi: $10.3102 / 0034654310364401$

Moon, J. (1999). Reflection in learning \& professional development: theory \& practice. London: Kogan Page.

Ohler, J. (2006). The world of digital storytelling. Educational leadership, 63(4), 44-47.

Ohler, J. (2008). Digital Storytelling in the Classroom. New Media Pathways to Literacy, Learning, and Creativity. Thousand Oaks: Corwin Press.

Partnership for 21st Century Learning. (2015). Framework for 21st Century Learning. Retrieved October 12, 2016, from http://www.p21.org/

Robin, B. R. (2006). The Educational Uses of Digital Storytelling. Technology and Teacher Education Annual, 1, 709.

Robin, B. R. (2008). Digital Storytelling: A Powerful Technology Tool for the 21 st Century Classroom. Theory Into Practice, 47(3), 220-228. doi: 10.1080/00405840802153916

Sadik, A. (2008). Digital Storytelling: A meaningful technology-integrated approach for engaged student learning. Educational Technology Research and Development, 56, 487-506. doi: 10.1007/s11423-008-9091-8

Smeda, N., Dakich, E., \& Sharda, N. (2012). Transforming Pedagogies Through Digital Storytelling: Framework and Methodology. 206-211.

Smeda, N., Dakich, E., \& Sharda, N. (2014). The effectiveness of digital storytelling in the classrooms: a comprehensive study. Smart Learning Environments, 1(1), 1-21. doi: 10.1186/s40561-014-0006-3

Stewart, K., \& Gachago, D. (2016). Being human today: A digital storytelling pedagogy for transcontinental border crossing. British Journal of Educational Technology, 47(3), 528-542. doi: 10.1111/bjet.12450

Tan, M., Lee, S.-S., \& Hung, D. W. L. (2014). Digital storytelling and the nature of knowledge. Education and Information Technologies, 19(3), 623-635. doi: 10.1007/s10639-013-9280-x

Voogt, J., \& Roblin, N. P. (2012). A comparative analysis of international frameworks for 21 st century competences: implications for national curriculum policies. Journal of curriculum studies, 44(3), 299-321.

Ware, P. D. (2006). From Sharing Time to Showtime! Valuing Diverse Venues for Storytelling in Technology-Rich Classrooms. Language Arts, 84(1), 45-54.

Weigel, V. B. (2002). Deep learning for a digital age: technology's untapped potential to enrich higher education. San Francisco: Jossey-Bass.

Wolcott, H. F. (1994). Transforming qualitative data: Description, analysis, and interpretation. London: Sage.

Xu, Y., Park, H., \& Baek, Y. (2011). A New Approach Toward Digital Storytelling: An Activity Focused on Writing Selfefficacy in a Virtual Learning Environment. Journal of Educational Technology \& Society, 14(4), 181-191.

Yang, Y. T. C., \& Wu, W. C. I. (2012). Digital storytelling for enhancing student academic achievement, critical thinking, and learning motivation: A year-long experimental study. Computers \& Education, 59(2), 339-352. doi: 10.1016/j.compedu.2011.12.012

Yuksel, P., Robin, B. R., \& McNeil, S. (2011). Educational uses of digital storytelling around the world. Paper presented at the Proceedings of Society for Information Technology \& Teacher Education International Conference. 